\title{
ОПРЕДЕЛЕНИЕ ТЕРРИТОРИЙ РИСКА ПО УРОВНЮ АЛИМЕНТАРНО- ЗАВИСИМЫХ ЗАБОЛЕВАНИЙ С УЧЕТОМ РЕГИОНАЛЬНЫХ ОСОБЕННОСТЕЙ СТРУКТУРЫ ПИТАНИЯ НАСЕЛЕНИЯ
}

\author{
Н. Ю. Самодурова ${ }^{1}$, Н. П. Мамчик ${ }^{1}$ А. В. Истомин ${ }^{\otimes}$, О. В. Клепиков ${ }^{3}$, Г. Г. Соколенко \\ Воронежский государственный медицинский университет имени Н. Н. Бурденко, Воронеж \\ ${ }^{2}$ Федеральный научный центр гигиены имени Ф. Ф. Эрисмана, Мытищи \\ ${ }^{3}$ Центр гигиены и эпидемиологии в Воронежской области, Воронеж \\ ${ }^{4}$ Воронежский государственный аграрный университет имени Петра I, Воронеж
}

\begin{abstract}
Проблема роста уровня алиментарно-зависимых заболеваний в настоящее время имеет глобальные масштабы. Целью исследования были изучение уровня потребления основных продуктов питания и оценка показателей алиментарнозависимых заболеваний населения Воронежской области. Баланс потребления продуктов питания изучали по данным территориального управления Росстата по Воронежской области за два пятилетних периода (1995-1999 гг. и 2012-2016 гг.). Анализ алиментарно-зависимой заболеваемости выполняли по данным обращаемости населения за медицинской помощью с последующим ранжированием показателей на отдельных территориях на пять уровней. За два пятилетних периода произошли существенные изменения в характере питания: увеличилось потребление в расчете на одного жителя рыбопродуктов, свежих фруктов, мяса и мясных продуктов, овощей и бахчевых, яиц, растительного масла, молока и молочных продуктов. Вместе с тем наблюдается избыточное потребление сахара, хлебных продуктов, картоселя - от 1,42 до 2,04 раз, что свидетельствует о преобладании в рационе углеводной составляющей. По результатам оценки, отмечается достоверное увеличение показателей заболеваемости ожирением до 4,5 раз, анемией, болезнями эндокринной системы (в 1,8-2 раза) и болезнями органов пищеварения (в 1,2 раза). Приоритеты в профилактике алиментарно-зависимой заболеваемости должны быть отданы территориям риска
\end{abstract}

Ключевые слова: сбалансированность питания, алиментарно-зависимое заболевание, структура питания

$\bigotimes$ Для корреспонденции: Александр Викторович Истомин

ул. Семашко, д. 2, г. Мытищи, 141014; erisman-istomin@yandex.ru

Статья получена: 25.06.2018 Статья принята к печати: 20.10.2018

DOI: $10.24075 /$ vrgmu.2018.056

\section{IDENTIFICATION OF DISTRICTS AT RISK OF NUTRIENT-RELATED DISEASES BASED ON THE LOCAL DIET}

Samodurova NYu ${ }^{1}$, Mamchik NP ${ }^{1}$, Istomin $\mathrm{AV}^{2} \otimes$, Klepikov OV ${ }^{3}$, Sokolenko GG ${ }^{4}$

${ }^{1}$ Voronezh State Medical University, Voronezh

${ }^{2}$ Erisman Federal Research Centre of Hygiene of Rospotrebnadzor, Mytishchi

${ }^{3}$ Center for Hygiene and Epidemiology in Voronezh Region, Voronezh

${ }^{4}$ Voronezh State Agricultural University, Voronezh

\begin{abstract}
The growing incidence of nutrient-related diseases is a global challenge. The aim of this work was to study consumption of staple food products and to estimate the incidence of nutrient-related diseases in Voronezh region. Food consumption was analyzed from the reports of the local branch of the Federal State Statistics collected over two 5-year periods (19951999 and 2012-2016). The incidence of nutrient-related diseases was estimated based on the reports providing information about patients' visits to healthcare facilities. The districts of Voronezh region were assigned to 5 ranks. Over the studied periods, the population of Voronezh region considerably changed its diet: consumption of fish and seafood, fresh fruits, meat, vegetables, gourds and melons, eggs, vegetable oil, milk and dairy products per person increased significantly. At the same time, consumption of sugar, breads and potatoes still exceeds the recommended intake 1.42-2.04-fold, which means that the main component of the diet is carbohydrates. We observed a significant 4.5-fold increase in obesity incidence, a 1.8-2.0-fold increase in the incidence of anemia and endocrine disorders and a 1.2 increase in the incidence of gastrointestinal diseases. In terms of prevention measures, the priority should be given to areas at a high risk of nutrient-related diseases.
\end{abstract}

Keywords: balanced nutrition, health risk of nutrition-related morbidity

$\triangle$ Correspondence should be addressed: Aleksandr V. Istomin,

Semaschko 2, Moscow region, Mytischi, 141014; erisman-istomin@yandex.ru

Received: 25.06.2018 Accepted: 20.10.2018

DOI: 10.24075/brsmu.2018.056

Проблема роста уровня алиментарно-зависимых заболеваний имеет глобальные масштабы, а выполнение задач по ее решению включено в государственные программы большинства развитых стран, в том числе Российской Федерации [1]. Оценка уровня алиментарно-зависимой заболеваемости населения и выявление ее причин - одна из задач социально-гигиенического мониторинга и реализации риск-ориентированной модели санитарноэпидемиологического надзора [2]. Результаты анализа информационно-аналитических материалов по алиментарно-зависимой патологии с оценкой риска здоровью населения свидетельствуют о росте уровня таких 
заболеваний в отдельных регионах России, в частности в Самарской области [3], Республике Татарстан [4], северных регионах [5].

Помимо анализа статистических данных в рамках системы социально-гигиенического мониторинга, целенаправленными исследованиями по оценке риска развития алиментарнозависимых заболеваний показана значимость проблемы у отдельных контингентов и с учетом региональных факторов. Так, на основе метода анкетного опроса и ведения пищевого дневника проведена оценка ежедневного фактического питания студентов, показавшая, что совокупность факторов несбалансированного питания, наследственной отягощенности, нерационального образа жизни приводит к появлению даже у молодого поколения таких болезней, как анемия, ожирение, сахарный диабет 2-го типа [6]. На примере изучения алиментарного статуса рабочих Арктической зоны России показан дисбаланс их фактического питания, что является фактором риска нарушения здоровья [7]. Проблема несбалансированности питания характерна и для стран ближнего зарубежья. В частности, результаты оценки фактического питания и состояния здоровья более 3000 человек, проживающих в городах и селах Центрального и Восточного Казахстана, позволили выявить недостаточную калорийность суточного рациона с десицитом поступления энергии с продуктами питания (12-19\%), низкий уровень поступления в организм витаминов С, В1, В2 и ниацина (47-73\% от рекомендуемой нормы поступления), 50\%-й десицит поступления ретинола и токоферола [8].

Установлено, что на отдельных территориях Российской Федерации ситуация с алиментарно-зависимой заболеваемостью и состоянием фактического питания населения значительно различается, в связи с чем проводятся научные исследования по выделению кластеров региональных особенностей [9, 10]. Последний факт делает актуальным проведение таких исследований в отдельных регионах России, они помогут при разработке и реализации мероприятий по обеспечению гигиенической безопасности и сбалансированности питания, профилактике алиментарно-зависимой заболеваемости с учетом региональных особенностей [11].

Целью исследования было изучить уровень потребления основных продуктов питания и оценить показатели алиментарно-зависимых заболеваний населения Воронежской области.

\section{МАТЕРИАЛЫ И МЕТОДЫ}

Исследование проводили на территории 32 районов Воронежской области с населением 2,3 млн человек. Баланс потребления продуктов питания изучали по данным территориального управления Росстата по Воронежской области за два пятилетних периода (1995-1999 гг. и 2012-2016 гг.), в течение которых были зарегистрированы различные изменения в объемах и структуре потребления 10 основных групп продуктов: хлебных продуктов; картофеля; овощей и бахчевых; свежих фруктов; сахара; мясопродуктов; рыбопродуктов; молока и молочных продуктов; яиц; масла растительного. Полученные данные оценивали в соответствии с «Рекомендуемыми рациональными нормами потребления пищевых продуктов, отвечающих современным требованиям здорового питания» (Приказ Министерства здравоохранения РФ от 19 августа 2016 г. № 614).

Анализ заболеваемости осуществляли с учетом данных Федеральной службы государственной статистики РФ (статистическая отчетная форма № 12 (годовая) «Сведения о числе заболеваний, зарегистрированных у пациентов, проживающих в районе обслуживания медицинской организации») за 1995-1999 п. и 2012-2016 г. с использованием пакета прикладных статистических программ Statistica 6.0 и Microsoft Office (Excel).

Для территориального ранжирования данных по среднему многолетнему уровню заболеваемости населения использовали алгоритм определения границ значений показателя исходя из его среднеобластной величины (М), среднего квадратического отклонения $(\sigma)$ по 5 уровням: 1-й ранг оценивался как «низкий» (от $М-\sigma$ и ниже), 2-й ранг — «ниже среднего» (от М - $\sigma$ до M - 0,5б), 3-й ранг -

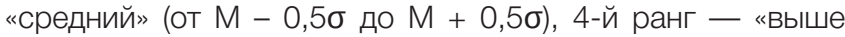
среднего» (от $\mathrm{M}+0,5 \sigma$ до $\mathrm{M}+\sigma$ ), 5-й ранг — «высокий» ( $\mathrm{M}+\sigma$ и выше). Территории с высоким уровнем СМУ (5-й ранг) отнесены к территориям риска.

\section{РЕЗУЛЬТАТЫ ИССЛЕДОВАНИЯ}

При сравнительном анализе данных о потреблении основных групп продуктов питания населением Воронежской области за 1995-1999 гг. и 2012-2016 гг. установлены существенные изменения в структуре питания (табл. 1). Так, при сравнении средних значений показателей

Таблица 1. Потребление основных продуктов питания населением Воронежской области за 1995-1999 гг. и $2012-2016$ гг. (на человека кг/год)

\begin{tabular}{|c|c|c|c|c|c|c|c|c|c|c|c|c|c|}
\hline \multirow{2}{*}{$\begin{array}{c}\text { Наименование } \\
\text { продуктов }\end{array}$} & \multirow{2}{*}{ Норма } & \multicolumn{5}{|c|}{ Период наблюдения, г } & \multirow{2}{*}{$\begin{array}{c}\text { Среднее за } \\
\text { 1995-1999 гг. }\end{array}$} & \multicolumn{5}{|c|}{ Период наблюдения, г } & \multirow{2}{*}{$\begin{array}{c}\text { Среднее за } \\
\text { 2012-2016 гг. }\end{array}$} \\
\hline & & 1995 & 1996 & 1997 & 1998 & 1999 & & 2012 & 2013 & 2014 & 2015 & 2016 & \\
\hline Хлебные продукты & 96 & 137 & 137 & 138 & 142 & 142 & 139 & 136 & 136 & 137 & 137 & 135 & 136 \\
\hline Картофель & 90 & 122 & 115 & 137 & 141 & 141 & 131 & 126 & 127 & 127 & 127 & 127 & 127 \\
\hline Овощи и бахчевые & 140 & 79 & 76 & 77 & 81 & 83 & 79 & 127 & 129 & 130 & 130 & 130 & 129 \\
\hline Фрукты свежие & 100 & 39 & 40 & 38 & 43 & 22 & 36 & 74 & 76 & 75 & 74 & 74 & 75 \\
\hline Caxap & 24 & 46 & 49 & 50 & 50 & 50 & 49 & 48 & 47 & 49 & 50 & 52 & 49 \\
\hline Мясопродукты & 73 & 53 & 46 & 45 & 44 & 43 & 46 & 83 & 91 & 89 & 90 & 92 & 89 \\
\hline Рыбопродукты & 22 & 7 & 8 & 7 & 6 & 6 & 7 & 22 & 22 & 23 & 23 & 22 & 22 \\
\hline $\begin{array}{l}\text { Молоко и } \\
\text { молокопродукты }\end{array}$ & 325 & 255 & 227 & 238 & 238 & 237 & 239 & 267 & 269 & 270 & 270 & 271 & 269 \\
\hline Яйца, штук & 260 & 246 & 242 & 233 & 222 & 223 & 233 & 329 & 334 & 338 & 338 & 339 & 336 \\
\hline Масло растительное & 12 & 11 & 11 & 10 & 11 & 11 & 11 & 15 & 15 & 15 & 15 & 16 & 15 \\
\hline
\end{tabular}


двух оцениваемых периодов установлено, что в расчете на одного жителя (кг/год) значительно возросло потребление рыбопродуктов - в 3,14 раза, свежих фруктов - в 2,08 раза, мяса и мясных продуктов - в 1,93 раза, овощей и бахчевых - в 1,63 раза, яиц (шт.) - в 1,44 раза, растительного масла - в 1,36 раза, молока и молочных продуктов в 1,13 раза. В то же время незначительно снизилось потребление картофеля, хлеба и хлебных продуктов, при неизменном уровне потребления сахара, составляющем 49 кг на человека в год.

При сравнении с рекомендуемым уровнем потребления (нормой) установлено, что современная региональная ситуация характеризуется избыточным (в 2,04 раза) потреблением сахара, хлебных продуктов (в 1,42 раза), при одновременном недостатке потребления продуктов высокой биологической ценности, прежде всего молока и молочных продуктов (сметаны, масла животного, творога, сыра, кефира, йогурта) - 83\% от рекомендуемой нормы потребления (т. е. ниже нормы в 1,21 раза), овощной продукции - важного источника витаминов и минеральных веществ (капусты, моркови, свеклы, лука, томатов, огурцов, перца сладкого, зелени, кабачков и др.) - 92\% от рекомендуемой нормы потребления (т. е. ниже нормы в 1,08 раза), а также свежих фруктов, в том числе яблок, груш, винограда, цитрусовых - 75\% от рекомендуемых размеров потребления (т. е. ниже нормы в 1,33 раза), что позволяет охарактеризовать фактическое питание населения Воронежской области преимущественно как «углеводную» модель потребления.

На фоне несбалансированного питания в сочетании, как правило, с воздействием неблагоприятных факторов окружающей среды у населения Воронежской области регистрируются алиментарно-зависимые заболевания. При сравнении средних многолетних уровней заболеваемости за рассматриваемые пятилетние периоды установлено, что рост числа случаев заболеваний на 1000 населения отмечается почти по всем рассматриваемым классам болезней и нозологиям в 1,2-4,5 раза, за исключением язвы желудка и двенадцатиперстной кишки. Наиболее сильно (в 4,5 раза) возрос уровень ожирения (табл. 2).

На основе анализа региональных данных, характеризующих средний многолетний уровень алиментарно-зависимых заболеваний на территории Воронежской области, построена пятиуровневая оценочная шкала, которая была использована для последующего ранжирования административных территорий (табл. 3).

По данным средних многолетних областных показателей за 2012-2016 гг., уровень заболеаний крови и кроветворных органов составляет 17,1 \pm 1,22 случая на 1000 человек населения, в том числе диагноз анемии выставлен в 3,7 \pm 0,26 случаях на 1000 человек населения. За период в целом по области выявлена тенденция роста уровня данной патологии $\left(R^{2}=0,829\right)$. Аналогичная ситуация отмечается в ряде административных районов, в том числе относительно благополучных, отнесенных в результате ранжирования к 1 рангу (0,6-2,2 случаев заболеваний на 1000 человек населения): Нижнедевицкий район - 1,6 случаев на 1000 человек (темп прироста составил 111,0\%); Верхнехавский район - 1,4 случаев на 1000 человек (темп прироста - 241,6\%); Хохольский район - 1,4 случаев на 1000 человек (темп прироста - 295,7\%); Терновский район - 0,6 случаев на 1000 человек (темп прироста 83,0\%). Территории области, отнесенные в результате ранжирования по уровню заболеваемости анемией $\mathrm{k}$ 5 рангу (4,7-6,8 случаев заболеваний на 1000 человек): Богучарский, Верхнемамонский и Калачеевский районы, имеют менее выраженный темп прироста (минус 33,3\%, 11,9\% и 30,8\% соответственно) на фоне максимальных показателей заболеваемости 4,7, 6,3 и 6,8 случаев заболеваний на 1000 человек соответственно.

Количество заболеваний эндокринной системы у населения Воронежской области с 2012 г. ежегодно увеличивалось, достигнув максимального показателя в 2015 г. - 73,3 случая на 1000 человек, при среднем многолетнем показателе заболеваемости, составившем 69,3 + 5,93 случая заболевания на 1000 человек. Выявлено

Таблица 2. Средние многолетние уровни заболеваемости населения Воронежской области, связанной с алиментарным фактором (на 1000 человек), Мџm

\begin{tabular}{|c|c|c|c|}
\hline \multirow{2}{*}{ Класс болезней или нозологическая форма } & \multicolumn{2}{|c|}{ Средний многолетний уровень заболеваемости за период } & \multirow{2}{*}{$\begin{array}{c}\text { Увеличение (+) } \\
\text { Снижение (-) } \\
\text { (число раз) }\end{array}$} \\
\hline & 1995-1999 гг. & 2012-2016 гг. & \\
\hline Болезни крови и кроветворных органов (всего) & $9,8 \pm 0,91$ & $16,1 \pm 1,22$ & $+1,6$ \\
\hline Анемия & $2,0 \pm 0,03$ & $3,7 \pm 0,26$ & $+1,8$ \\
\hline Болезни эндокринной системы (всего) & $33,3 \pm 0,36$ & $69,3 \pm 5,93$ & $+2,0$ \\
\hline Ожирение & $2,5 \pm 0,04$ & $11,3 \pm 2,58$ & $+4,5$ \\
\hline Болезни органов пищеварения (всего) & $78,6 \pm 0,22$ & $97,4 \pm 4,91$ & $+1,2$ \\
\hline Язва желудка и двенадцатиперстной кишки & $15,5 \pm 0,03$ & $12,9 \pm 0,13$ & $-0,8$ \\
\hline Гастрит и дуоденит & $15,1 \pm 0,06$ & $21,9 \pm 1,08$ & $+1,5$ \\
\hline
\end{tabular}

Таблица 3. Шкала для ранжирования территорий Воронежской области по уровню алиментарно-зависимых заболеваний (интервал числа случаев заболеваний на 1000 человек)

\begin{tabular}{|c|c|c|c|c|c|}
\hline Нозологии & $\begin{array}{c}\text { 5-й ранг } \\
\text { («высокий») }\end{array}$ & $\begin{array}{c}\text { 4-й ранг } \\
\text { («выше среднего») }\end{array}$ & $\begin{array}{c}\text { 3-й ранг } \\
\text { («средний») }\end{array}$ & $\begin{array}{c}\text { 2-й ранг } \\
\text { («ниже среднего») }\end{array}$ & $\begin{array}{c}1-и ̆ \text { ранг } \\
(« н и з к и и ̆ »)\end{array}$ \\
\hline Болезни крови и кроветворных органов (всего) & $22,3-25,7$ & $20,3-22,2$ & $14,2-20,3$ & $8,1-14,1$ & $4,6-14,0$ \\
\hline Анемии & $4,7-6,8$ & $3,9-4,6$ & $2,4-3,8$ & $1,6-2,3$ & $0,6-2,2$ \\
\hline Болезни эндокринной системы (всего) & $77,9-110,3$ & $68,9-77,8$ & $51,1-68,8$ & $42,1-51,0$ & $26,4-42,0$ \\
\hline Ожирение & $13,7-26,5$ & $10,9-13,6$ & $5,3-10,8$ & $2,5-5,2$ & $0,5-2,4$ \\
\hline Болезни органов пищеварения (всего) & $129,8-212,9$ & $110,9-129,7$ & $73,5-110,8$ & $54,8-73,4$ & $46,1-54,7$ \\
\hline Язва желудка и двенадцатиперстной кишки & $17,8-28,2$ & $15,5-17,7$ & $10,9-15,4$ & $8,5-10,8$ & $6,7-8,4$ \\
\hline Гастрит и дуоденит & $29,4-47,8$ & $24,8-29,3$ & $15,6-24,7$ & $11,1-15,5$ & $4,1-11,0$ \\
\hline
\end{tabular}


5 административных районов с наибольшими показателями заболеваемости, отнесенных к 5 рангу $(77,9-110,3$ случая на 1000 человек): Бобровский - 110,3 случая на 1000 человек, Рамонский - 89,2 случая на 1000 человек; Павловский - 81,4 случая на 1000 человек, Подгоренский 81,2 случая на 1000 человек, Ольховатский - 80,1 случая на 1000 человек.

При анализе уровня показателей заболеваемости населения ожирением установлено, что только в восьми районах из 32 не был зарегистрирован рост заболеваемости: Бобровском, Борисоглебском, Бутурлиновском, Воробьевском, Калачеевском, Новоусманском, Панинском и Таловском районах. С учетом ранжирования территорий области по уровню заболеваемости ожирением ряд районов отнесены к 5 рангу (13,7-26,5 случаев заболеваний на 1000 населения): Каширский - 26,5 случаев на 1000 человек (темп прироста - 637,5\%); Верхнехавский - 20,3 случая на 1000 человек (темп прироста - 245,0\%); Терновский - 17,5 случаев на 1000 человек (темп прироста 394,1\%); Рамонский - 17,2 случая на 1000 человек (темп прироста - 133,4\%); Бобровский - 17,1 случай на 1000 человек (темп прироста - 118,4\%); Хохольский - 16,9 случаев на 1000 человек (темп прироста - 710,5\%).

В настоящее время средняя многолетняя заболеваемость населения Воронежской области болезнями органов пищеварения составляет 97,4 \pm 4,91 случаев заболеваний на 1000 человек и имеет стойкую тенденцию к росту $\left(R^{2}=0,927\right)$. В результате ранжирования административных территорий выделены районы с максимальными показателями заболеваемости (5-й ранг; 129,8-212,9 случаев заболеваний на 1000 человек): Репьевский - 212,9 случаев на 1000 человек; Поворинский - 182,9 случаев на 1000 человек и Таловский 172,1 случаев на 1000 человек. Районы с минимальными показателями (1-й ранг; 46,1-54,7 случаев заболеваний на 1000 человек): Верхнехавский - 46,1 случая на 1000 человек, Ольховатский - 52,9 случаев на 1000 человек и Эртильский - 53,5 случаев на 1000 человек.

В показателях заболеваемости населения язвой желудка и двенадцатиперстной кишки при сравнении двух анализируемых периодов отмечается тенденция к снижению: с 15,5 \pm 0,03 до 12,9 \pm 0,13 случаев на 1000 человек (на 17\%). Вместе с тем, по уровню средней многолетней заболеваемости (2012-2016 гг.) выявлены 4 района с максимальными показателями, отнесенные к рангу 5 («высокий»): Калачеевский - 28,2 случая заболевания на 1000 человек, Таловский - 21,8 случая на 1000 человек; Кантемировский - 21,7 случаев на 1000 человек и Терновский - 17,8 случаев на 1000 человек. Однако даже стабильно высокие многолетние показатели в темпе прироста в целом отражают снижение уровня.

Следует также отметить, что административные территории с наименьшим уровнем заболеваемости, отнесенные в результате ранжирования к рангу 1 («низкий»): Верхнехавский, Нижнедевицкий и Репьевский районы (6,7-8,5 случаев заболеваний на 1000 человек населения), вызывают большее опасение в плане дальнейшего прогноза: темп прироста заболеваемости язвой желудка и двенадцатиперстной кишки за последний пятилетний период наблюдения по этим районам был наибольшим и составил 63,93\%, 68,04\% и 139,04\% соответственно.

Средний по области показатель заболеваемости гастритом и дуоденитом составляет 21,9 $\pm 1,1$ случая на 1000 человек с темпом прироста за последний пятилетний период $16,6 \%\left(R^{2}=0,879\right)$. В результате ранжирования административных территорий по среднему многолетнему уровню заболеваемости выявлены районы, отнесенные к 5 рангу (29,4-47,8 случаев заболеваний на 1000 человек): Таловский район - 47,8 случаев на 1000 человек (темп прироста - 4,7\%), Каменский - 39,7 на 1000 человек (темп прироста - 6,8\%), Репьевский - 32,6 на 1000 человек (темп прироста - 33,8\%); Воробьевский - 30,31 случая на 1000 человек (темп прироста - 100,1\%), Нижнедевицкий 29,5 случая на 1000 человек (темп прироста - 12,9\%). $\mathrm{K}$ рангу 1 с наименьшими показателями заболеваемости отнесены: Верхнехавский, Каширский, Лискинский и Панинский районы (4,1-11,0 случаев заболеваний на 1000 человек); однако в них отмечается наибольший прирост заболеваемости (60,02-203,21\%).

\section{ОБСУЖДЕНИЕ РЕЗУЛЬТАТОВ}

Выборочный анализ данных по потреблению продуктов питания населением Воронежской области за два пятилетних периода (1995-1999 гг. и 2012-2016 гг.) показал существенные изменения в характере питания, выражающиеся в увеличении потребления в расчете на одного жителя рыбопродуктов, свежих фруктов, мяса и мясных продуктов, овощей и бахчевых, яиц, растительного масла, молока и молочных продуктов. Вместе с тем, по отношению к рекомендуемой норме потребления современная региональная ситуация характеризуется избыточным потреблением сахара, хлебных продуктов, картофеля (в 1,42-2,04 раз), что свидетельствует о преобладании в рационе углеводной составляющей.

Аналогичный анализ ситуации был проведен в северных регионах, в ходе которого установлено, что потребление продуктов питания является несбалансированным и характеризуется недостаточным потреблением мяса и мясопродуктов, рыбы и морепродуктов, молока и молочных продуктов, ненасыщенных жиров при избыточном потреблении насыщенных жиров, хлебных продуктов [5]. Общим для Центрального Черноземья (Воронежской области) и регионов Севера является избыточное потребление хлеба и хлебопродуктов, которое регистрируется на протяжении многолетнего периода [12].

По результатам оценки алиментарно-зависимой заболеваемости населения Воронежской области, на фоне несбалансированного питания в течение изучаемых пятилетних периодов отмечается достоверное увеличение показателей заболеваемости ожирением (в 4,5 раза), анемией, болезнями эндокринной системы (в 1,8-2 раза) и болезнями органов пищеварения (в 1,2 раза). Тревожность данных негативных тенденций подчеркнута в работах ряда авторов, посвященных вопросам организации питания и анализа алиментарно-зависимой заболеваемости. В частности, наибольшую актуальность эти вопросы имеют для такого контингента, как студенты, для которых отмечается крайне несбалансированное питание в сочетании с нарушениями режима приема пищи [13].

Изучение детерминантов адаптационных резервов организма подростков Крайнего Севера и средней полосы РФ, проведенное на основе анализа показателей обменных процессов и состояния иммунитета, выявило изменения иммунологических и биохимических показателей состояния здоровья школьников под влиянием фактора несбалансированного питания, при этом адаптивное напряжение организма более выражено у школьников Крайнего Севера [14]. 
Рост показателей алиментарно-зависимых заболеваний диктует необходимость обоснования и реализации комплекса целенаправленных просилактических мероприятий, формирования инновационных подходов к гигиенической и медико-биологической оценке безопасности пищи в Российской Федерации [15].

Выполненное нами ранжирование показателей алиментарно-зависимой заболеваемости и выявление территорий риска лишь подготавливают основу решения региональной проблемы обеспечения здорового и безопасного питания населения. По нашим данным, приоритеты в профилактике алиментарно-зависимой заболеваемости должны быть отданы территориям риска. Одним из методов профилактики такой заболеваемости является включение в рационы организованных коллективов, где это возможно и целесообразно, продуктов, обладающих выраженным действием при тех или иных патологических состояниях организма, а также повышающих его естественную устойчивость [16]. При этом обращается внимание на совершенствование нормативнометодической базы в сфере специализированной пищевой продукции [17]. В Воронежском регионе имеются положительные примеры реализации программ по профилактике фтор- и йоддесицитных состояний
[12], снижению уровня контаминации продуктов питания на основе изучения медико-биологических проблем взаимосвязи качества продуктов питания и процессов свободнорадикального окисления в организме [18]. Вместе с тем проблема обеспечения сбалансированного питания является комплексной и требует дальнейшего детального изучения многих отдельных вопросов.

\section{ВЫВОДЫ}

Проведенное исследование позволило выявить негативные изменения в структуре питания населения Воронежской области, выражающиеся в избыточном потреблении углеводсодержащих продуктов (хлеба и хлебопродуктов, картофеля), при дефиците продуктов с высокой биологической ценностью (молоко, молочные продукты, свежие овощи и фрукты). На фоне несбалансированного питания установлен рост алиментарно-зависимых заболеваний (болезни эндокринной системы, ожирение, болезни органов пищеварения).

Полученные результаты позволили выявить территории риска по уровню алиментарно-зависимой патологии для последующего обоснования мероприятий по оптимизации структуры и качества питания населения.

\section{Литература}

1. Ким М. Н. Тенденции развития алиментарно-зависимых заболеваний и роль функциональных продуктов в профилактике заболеваний. Евразийский союз ученых. 2016; 1-2 (22): 65-8.

2. Попова А. Ю., Зайцева Н. В., Май И. В. Опыт методической поддержки и практической реализации риск-ориентированной модели санитарно-эпидемиологического надзора: 2014-2017 гг. Гигиена и санитария. 2018; 97 (1): 5-9.

3. Сергеева Н. М., Цунина Н. М., Афанасьева Н. Ю., Жернов Ю. В., Аюпова Л. В. Результаты изучения эндемической патологии, связанной с алиментарным фактором. Здоровье населения и среда обитания. 2015; 1 (262): 6-11.

4. Фролова О. А., Тафеева Е. А., Фролов Д. Н., Бочаров Е. П. Алиментарно-зависимые заболевания населения и гигиеническая характеристика факторов риска их развития на территории Республики Татарстан. Гигиена и санитария. 2018; 97 (5): 470-3.

5. Гогадзе Н. В., Турчанинов Д. В., Юнацкая Т. А., Вильмс Е. А., Сохошко И. А. Гигиеническое обоснование совершенствования системы надзора за питанием и профилактики алиментарнозависимых заболеваний в Северном регионе России. Современные проблемы науки и образования. 2014; (6): с. 1129.

6. Мельникова М. М. Несбалансированное питание как фактор риска развития алиментарно-зависимых заболеваний. Вестник Новосибирского государственного педагогического университета. 2014; 1 (17): 197-202.

7. Никанов А. Н., Талыкова Л. В., Быков В. Р., Табарча О. И. Влияние лечебно-профилактических напитков на минеральный обмен промышленных рабочих Арктической зоны Российской Федерации. Вестник Кольского научного центра РАН. 2017; (4): 113-8.

8. Ахметова С. В., Терехин С. П., Назар Д. К., Ашимова С. К., Сейлханова Ж. А., Мхитарян К. Э. и др. Особенности питания лиц с риском развития неинфекционных алиментарнозависимых заболеваний. Вопросы питания. 2015; 84 (5): с. 14.

9. Вторушина А. В. Региональные особенности становления общества потребления в России: анализ структуры питания. Журнал социологии и социальной антропологии. 2011; 14 (5): 252-9.
10. Государственный доклад «О состоянии санитарноэпидемиологического благополучия населения в Российской Федерации в 2017 году». М.: Федеральная служба по надзору в сфере защиты прав потребителей и благополучия человека, 2018.

11. Перекусихин М. В., Васильев В. В. Оценка качества и безопасности продовольственного сырья и пищевых продуктов, питания населения в системе социальногигиенического мониторинга и обеспечения здоровья. Медицина труда и экология человека. 2015; (4): 264-9.

12. Рослякова Е. В., Чубирко М. И., Пичужкина Н. М., Масайлова Л. А. Роль факторов среды обитания в формировании риска йоддесицитных заболеваний. Здравоохранение Российской Федерации. 2009; (3): 48-50.

13. Суворова А. А., Суханова Д. Н., Мухитова М. Э. К вопросу о рациональном питании молодежи. Современные научные исследования и разработки. 2016; (3): 393-5.

14. Крючкова Е. Н., Истомин А. В., Сааркоппель Л. М., Яцына И. В. Детерминанты адаптационных резервов организма подростков различных регионов. Здравоохранение Российской Федерации. 2017; 61 (3): 143-7.

15. Тутельян В. А., Никитюк Д. Б., Хотимченко С. А. Нормативная база оценки качества и безопасности пищи. Российский журнал восстановительной медицины. 2017; (2): 74-120.

16. Манжесов В. И., Максимов И. В., Ухина Е. Ю., Рязанцева А. О., Курчаева Е. Е. Разработка продуктов направленного действия на основе комплексного использования биомодифицированного вторичного мясного и растительного сырья. Технологии и товароведение сельскохозяйственной продукции. 2018; 1 (10): 121-8.

17. Тутельян В. А., Жилинская Н. В., Саркисян В. А., Кочеткова А. А. Анализ нормативно-методической базы В ссере специализированной пищевой продукции в Российской Федерации. Вопросы питания. 2017; 86 (6): 29-35.

18. Цикуниб А. Д., Юдина Т. В., Истомин А. В., Клепиков О. В. Медико-биологические проблемы взаимосвязи качества продуктов питания и состояния свободнорадикального окисления в организме. Вопросы питания. 2000; 69 (5): 28-31. 


\section{References}

1. Kim MN. Tendencii razvitija alimentarno-zavisimyh zabolevanij $\mathrm{i}$ rol' funkcional'nyh produktov v profilaktike zabolevanij. Evrazijskij sojuz uchenyh. 2016; 1-2 (22): 65-8.

2. Popova AJu, Zajceva NV, Maj IV. Opyt metodicheskoj podderzhki i prakticheskoj realizacii risk-orientirovannoj modeli sanitarnojepidemiologicheskogo nadzora: 2014-2017 gg. Gigiena i sanitarija. 2018; 97 (1): 5-9.

3. Sergeeva NM, Cunina NM, Afanaseva NJu, Zhernov JuV Ajupova LV. Rezul'taty izuchenija jendemicheskoj patologii, svjazannoj s alimentarnym faktorom. Zdorov'e naselenija i sreda obitanija. 2015; 1 (262): 6-11.

4. Frolova OA, Tafeeva EA, Frolov DN, Bocharov EP. Alimentarnozavisimye zabolevanija naselenija i gigienicheskaja harakteristika faktorov riska in razvitija na territorii Respubliki Tatarstan. Gigiena i sanitarija. 2018; 97 (5): 470-3.

5. Gogadze NV, Turchaninov DV, Junackaja TA, Vil'ms EA, Sohoshko IA. Gigienicheskoe obosnovanie sovershenstvovanija sistemy nadzora za pitaniem i profilaktiki alimentarno-zavisimyh zabolevanij v Severnom regione Rossii. Sovremennye problemy nauki i obrazovanija. 2014; (6): s. 1129.

6. Melnikova MM. Nesbalansirovannoe pitanie kak faktor riska razvitija alimentarno-zavisimyh zabolevanij. Vestnik Novosibirskogo gosudarstvennogo pedagogicheskogo universiteta. 2014; 1 (17): 197-202.

7. Nikanov AN, Talykova LV, Bykov VR, Tabarcha OI. Vlijanie lechebno-profilakticheskih napitkov na mineral'nyj obmen promyshlennyh rabochih Arkticheskoj zony Rossijskoj Federacii. Vestnik Kol'skogo nauchnogo centra RAN. 2017; (4): 113-8.

8. Ahmetova SV, Terehin SP, Nazar DK, Ashimova SK, Sejhanova ZhA, Mhitarjan KJe. i dr. Osobennosti pitanija lic s riskom razvitija neinfekcionnyh alimentarno-zavisimyh zabolevanij. Voprosy pitanija. 2015; 84 (5): s. 14.

9. Vtorushina AV. Regional'nye osobennosti stanovlenija obshhestva potreblenija $\vee$ Rossii: analiz struktury pitanija. Zhurnal sociologii i social'noj antropologii. 2011; 14. (5): 252-9.
10. Gosudarstvennyj doklad «O sostojanii sanitarnojepidemiologicheskogo blagopoluchija naselenija $\vee$ Rossijskoj Federacii v 2017 godu». M.: Federal'naja sluzhba po nadzoru v sfere zashhity prav potrebitelej i blagopoluchija cheloveka, 2018.

11. Perekusihin MV, Vasil'ev W. Ocenka kachestva i bezopasnosti prodovol'stvennogo syr'ja i pishhevyh produktov, pitanija naselenija $v$ sisteme social'no-gigienicheskogo monitoringa obespechenija zdorov'ja. Medicina truda i jekologija cheloveka. 2015; (4): 264-9.

12. Rosljakova EV, Chubirko MI, Pichuzhkina NM, Masajlova LA. Rol' faktorov sredy obitanija $v$ formirovanii riska joddeficitnyh zabolevanij. Zdravoohranenie Rossijskoj Federacii. 2009; (3): 48-50.

13. Suvorova AA, Suhanova DN, Muhitova MJe. K voprosu o racional'nom pitanii molodezhi. Sovremennye nauchnye issledovanija i razrabotki. 2016; (3): 393-5.

14. Krjuchkova EN, Istomin AV, Saarkoppel LM, Jacyna IV. Determinanty adaptacionnyh rezervov organizma podrostkov razlichnyh regionov. Zdravoohranenie Rossijskoj Federacii. 2017; 61 (3): 143-7.

15. Tuteljan VA, Nikitjuk DB, Hotimchenko SA. Normativnaja baza ocenki kachestva i bezopasnosti pishhi. Rossijskij zhurnal vosstanovitel'noj mediciny. 2017; (2): 74-120.

16. Manzhesov VI, Maksimov IV, Uhina EJu., Rjazanceva AO, Kurchaeva EE. Razrabotka produktov napravlennogo dejstvija na osnove kompleksnogo ispol'zovanija biomodificirovannogo vtorichnogo mjasnogo i rastitel'nogo syr'ja. Tehnologii i tovarovedenie sel'skohozjajstvennoj produkcii. 2018; 1 (10): 121-8.

17. Tuteljan VA, Zhilinskaja NV, Sarkisjan VA, Kochetkova AA. Analiz normativno-metodicheskoj bazy $\vee$ sfere specializirovannoj pishhevoj produkcii v Rossijskoj Federacii. Voprosy pitanija. 2017; 86 (6): 29-35.

18. Cikunib AD, Judina TV, Istomin AV, Klepikov OV. Medikobiologicheskie problemy vzaimosvjazi kachestva produktov pitanija i sostojanija svobodnoradikal'nogo okislenija v organizme. Voprosy pitanija. 2000; 69 (5): 28-31. 